\title{
Pedagogical Talking Circles: Decolonizing Education through Relational Indigenous Frameworks
}

\author{
Patricia Barkaskas ${ }^{\mathrm{i}}$ \\ University of British Columbia \\ Derek Gladwin \\ University of British Columbia
}

\begin{abstract}
This article focuses on pedagogical talking circles as a practice of decolonizing and Indigenizing education. Based upon Canada's Truth and Reconciliation Commission's (TRC) Calls to Action and the United Nations Declaration on the Rights of Indigenous Peoples (UNDRIP), non-Indigenous educators have a responsibility, while Indigenous educators have an opportunity, to transform normative colonial institutional knowledge structures and practices. Pedagogical talking circles are particularly useful in providing supported spaces for participants/students to engage in reciprocal and relational learning. The pedagogical theories outlined in this article utilize three main Indigenous methodological approaches: situated relatedness, respectful listening, and reflective witnessing. Based upon these underlying approaches, this article speaks to the necessity for decolonizing education (K-12 and post-secondary).
\end{abstract}

\section{Intentions and Contexts}

Indigenous pedagogies and methodologies are increasingly being used in educational contexts throughout Canada and around the world. ${ }^{\text {ii }}$ They offer mechanisms to reconsider the privileging of certain kinds of knowledge over others, while addressing the politics of knowledge, within extant colonial education systems (Kovach, 2009). They also provide ways of considering 
education from a variety of different non-normative frameworks, such as qualitative subjective experiences, storytelling, and holistic knowledge. And yet, these perspectives are not "new" paradigms, despite their peripheral status in Eurocentric educational institutions. As Emerson claims, "new ways of knowing and being" are so "old" that they "look new" (Emerson, 2014, p. $58)$.

There are many Indigenous frameworks to draw on for developing effective teaching practices and methods. In this article, we focus on pedagogical talking circles, which are particularly beneficial in providing supported spaces for students to engage in reciprocal and relational learning. Talking circles, which are sometimes referred to as sharing circles or more broadly as circle work, are used in many contexts across different Indigenous traditions and cultures. However, not all Indigenous cultures use them. Circles of various kinds have been and continue to be used by other cultural and educational communities (Cowan \& Adams, 2002; Wilken \& Nunn, 2017; Zizka, 2017). Communities use talking circles as part of ceremonial, healing, educational, and legal systems, depending upon intentions and contexts, and also use them as a way of bringing people together to pass on cultural knowledges, practices, and values.

Talking circles build dialogue and create spaces of mutual respect for social discourse (Running Wolf \& Ricard, 2003; Kaminski, 2011; Di Lallo, Graham, \& Arian, 2018). Used as a method of communication, understanding, and education, talking circles showcase an alternative pedagogical practice that encourages people to listen openly to other viewpoints and perspectives that may differ from their own (Sams, 1990). Many educators, health practitioners, community leaders, youth organizers, and recovery centres have adopted talking circle practices because they cultivate effectively qualities of listening, compassion, and empathy that support healing and well-being (see further discussion in the next section).

When educators engage in the work of learning how to apply talking circles respectfully and with proper attentiveness to the Indigenous pedagogy and methodology of circle work, they can create truly transformative spaces for correlative understanding. We are intentionally cowriting this article as Indigenous and non-Indigenous authors (more on how we are specifically situated below). ${ }^{\text {iii }}$ As educators in the faculties of Education and Law in the Canadian postsecondary institution of the University of British Columbia - located on the traditional, ancestral, and unceded territory of the $\mathrm{x}^{\mathrm{w}} \mathrm{m} \partial \theta \mathrm{k}^{\mathrm{w}}$ əy่วm (Musqueam) - we use pedagogical talking circles as a praxis in all of our courses regardless of the subject (although the subject sometimes directly relates to Indigenous education).

We maintain that pedagogical talking circles provide one successful method of destabilizing and rewriting the narrative of Eurocentric educational systems, where students can feel supported when expressing themselves about challenging concepts, topics, and/or histories. Such approaches increase intercultural awareness for homogenized and heterogenous groups of participants, promoting diversity and intercultural competencies, as well as developing noncognitive qualities often neglected in Eurocentric educational contexts, such as somatic or emotional intelligence. As Kovach (2021) suggests, this work is built upon relationality; it is about knowing each other. The ultimate goal is helping students to understand their relationship to Indigenous peoples, communities, and Nations and that students in what is now called Canada 
are always on traditional territories - some Treatied and others unceded - of sovereign Indigenous Nations who still exist and have a right to exercise their inherent jurisdiction (Barkaskas, 2020). Coupal (2020) offers the term "redress" as a way to describe the space between "truth and reconciliation," providing a step toward the desired outcome of decolonization and Indigenization. For Indigenous students, we also hope this work assists them by reducing the burden of educating their fellow non-Indigenous students.

The talking circle pedagogy we discuss here is not culturally specific, ceremonial, or sacred Indigenous knowledge. It is a teaching and learning system grounded in Indigenous relational approaches that, in our particular contexts, relies on certain Indigenous methodologies developed through our own pedagogical experiences. In doing this work, educators must honour the Indigenous epistemological frameworks of circle praxis, which may differ depending on the context in which they have been taught and learned it.

The work of bringing Indigenous teaching practices into the classroom of colonial institutions is not necessarily easy and must be taken up with full acknowledgment of its source, and where and how the educator was taught to do this work (Archibald, 2013). It is increasingly important to build decolonial practices into our classrooms and teaching spaces (Battiste, 2013). When using considered protocols, talking circles create opportunities for educational spaces to become sites of transformative learning, where Indigenous knowledge systems can be honoured and respected while also taking up the calls to decolonize institutions.

As educators, who are Indigenous and non-Indigenous, we believe that the work of transforming and decolonizing institutions is essential. This work, as Kimmerer (2021) acknowledges, offers a significant opportunity to heal and move into a future where Indigenous principles guide us into new relationships with each other, our more-than-human relations, including the land, air, and water we all share. Indigenous peoples, communities, and Nations' culturally specific and sacred Indigenous knowledge must also be protected and not appropriated or exploited. We believe that Indigenous approaches to teaching and learning, when taken up mindfully and respectfully, provide meaningful, relevant, and appropriate ways to decolonize K12 and post-secondary institutions.

As a supportive and decolonizing learning space, our Indigenous pedagogical approach to talking circles draws on three main principles: situated relatedness (Johnston, 2018), respectful listening (Johnston, 2018), and reflective witnessing (Clark, 2016; Hunt, 2018). It is our belief and experience that we learn by creating, storytelling, reflecting, observing, and listening. Our intention in presenting a critical scaffolding behind talking circle pedagogy is to reinforce how it can be adopted responsibly by both Indigenous and non-Indigenous educators and participants as a relational framework: creating spaces for students/participants to develop deeper understanding through relationship building and learning in diverse environments. 


\section{Building on the Literature}

Previous literature shows how circles have been used in various formats, including community groups, health education, hospitality management, recovery groups, and in arts-based education (often drawing on forms of storytelling). Hodge, Fredricks, and Rodriguez (1996) explore the benefits of using talking circles to communicate culturally acceptable cervical cancer screening in urban and rural Indigenous health clinics in California. Haozous et al. (2010) similarly examine talking circles in health education, particularly in the ways they communicate cultural understanding for a community of Comanche women undergoing breast cancer screening and the treatment options available to them. Wilken and Nunn (2017) also explore talking circles as a lens into self-care health management. Granillo et al. (2010) surveys the communication methods of talking circles between community health representatives and tribal communities about serious health issues. Picou (2000) employs talking circles as a way to address disaster impacts with specific Indigenous communities in Alaska who suffered from the Exxon Valdez oil spill.

Among those who have outlined talking circles as a tool of pedagogy and learning, Running Wolf and Ricard (2003) underscore intercultural awareness emerging from instructional approaches to talking circles, a process that fosters respect for individual differences to facilitate group cohesion. Fickel (2005) considers how talking circles facilitated by teachers who have worked with Elders can enhance learning outcomes for K-12 students. Tachine, Yellow Bird, and Cabrera (2016) position talking circles (what they call "sharing circles," resembling focus groups) as a methodological approach to understand Indigenous students who are transitioning into colleges and universities. Zizka (2017) identifies talking circles as a method to encourage safe communication, specifically sharing and empathy, in community-based contexts of hospitality management education. Some of the literature also emphasizes the methodology of storytelling in talking circles practices (Zizka, 2017; Tachine, Yellow Bird, \& Cabrera, 2016).

Even while considering this earlier literature, Indigenous pedagogical and methodological frameworks for talking circles have largely remained peripheral in scholarly publications. This is particularly the case in the Canadian context (most of the aforementioned scholarship on talking circles focuses on the United States). Although the literature demonstrates the effectiveness of Indigenous talking circle practices in various public health, community, and social contexts, our contribution proposes to illuminate the educational context of teaching and learning as part of a commitment to decolonizing and Indigenizing education.

Our intention is to provide some critical scaffolding to bolster the doing of talking circles.

We introduce specific theories that support talking circles as a pedagogical framework and praxis and use specific methodologies that aim to decolonize and Indigenize Eurocentric (colonial) educational spaces. The purpose of this pedagogical research is generative and pluralistic rather than hierarchical deficit discourse, and it seeks to provide alternatives to the normative educational practices in K-12 or post-secondary education. Colonial influence on educational systems has not only created symbolic and literal violence upon colonized peoples, but it also hinders the cognitive and emotional development of all learners in the process of learning and meaning-making. 


\section{Decolonizing and Indigenizing Education}

Using pedagogical talking circles - as a way to decolonize education and promote Indigenous epistemologies, knowledges, perspectives, languages, histories, and pedagogies to focalize Indigenous ways of knowing and being - builds on the recommendations of the United Nations Declaration on the Rights of Indigenous Peoples (UNDRIP) (2007) and Truth and Reconciliation Commission of Canada (TRC), particularly as embedded in the Calls to Action (2015). Educators have already recognized and responded to the fact that education is a paramount concern for changing the course of Indigenous-settler relations in what is now called Canada (Hare and Davidson, 2016; Barkaskas, 2020; Donnan, Aitken, and Manore, 2020; Grafton and Melançon, 2020; Pardy and Pardy, 2020).

The Chair of the TRC, The Honourable Murray Sinclair, noted in advance of the release of the 2015 TRC findings and Calls to Action that education serves as both the problem and solution. Sinclair stated in a CBC interview: "Education is what got us into this mess - the use of education at least in terms of residential schools - but education is key to reconciliation" (as cited in Watters, 2015, para. 16). One of the many catastrophic effects of the Residential Schools, and why both truth and reconciliation remain vital for transformational change, is that Indigenous knowledges were suppressed through a systemic process of devaluation and discreditation (Cote-Meet, 2020). They were replaced with Eurocentric forms of "cognitive imperialism" (Battiste, 2000, p. 198). Reclaiming education through Indigenizing frameworks supports the TRC's Calls to Action as an immediate response to a legacy of colonialism and as a way to reconsider building sustainable educational futures with Indigeneity and associated knowledge systems as a primary focus.

Based upon the TRC's Calls to Action, many Indigenous and non-Indigenous educators have accelerated their commitment to decolonize. According to Cote-Meek (2020):

There is no doubt that the TRC (2015) has been important in terms on mobilizing action. The TRC calls on post-secondary institutions to engage in the reconciliation process and essentially lead change in education that promotes awareness and understanding and importantly integrates Indigenous histories, knowledges, and pedagogies in the classroom. Recognizing that there are long-standing colonial practices that remain deeply entrenched within the educational system, there are significant challenges and complexities to bringing about meaningful change. (p. xi)

In order to address and build on these imperatives and contribute to sustainable social and cultural futures, it is vital to foster decolonizing understandings of education in Canada.

Colonial frameworks continually influence common knowledge paradigms upheld in K12 and post-secondary education (Kovach, 2009). Normative education in Canada perpetuates settler colonial perspectives as part of the ongoing violence of colonization, where curricula, pedagogies, and educational structures have historically been used as tools of dispossession and oppression. Following the TRC's Calls to Action, educating requires interrupting hegemonic 
practices by engaging with pedagogical approaches that resist dominant discourses about the power and purpose of education models that have been largely derived from settler colonial systems.

Decolonizing and Indigenizing education across Canada, and elsewhere around the world, challenges not only Eurocentric models of education that stem from colonialism; it also builds upon Indigenous knowledges that support learning through paradigms that reconstitute Indigenous ways of knowing (epistemological) and being (ontological) (Kovach, 2009; Battiste, 2013; Styres, 2017; Simpson, 2017; Cote-Meek and Moeke-Pickering, 2020; Galla and Holmes, 2020). Integrating Indigenous methodology and pedagogy in both the academic and practical aspects of education intervene in the normative violence of education and challenge the colonial hegemony underpinning the Canadian educational system (Battiste, 2013; Cote-Meek, 2014). Based upon the TRC's reports and Calls to Action, as well as the explicit need to promote Indigenous ways of knowing and being in our sociocultural and educational contexts on a mass scale (e.g., see UNDRIP), we hold the view that non-Indigenous educators have a responsibility, while Indigenous educators have an opportunity, to transform the normative colonial institutional knowledge structures and practices.

Talking circles fundamentally support Indigenization in ways that are relational, emphasizing meaning-making between and among groups of people rather than as individuals isolated in the process. When meaning is made through relationships rather than through individualistic paradigms that reify hierarchical power, the roots of oppression - othering and binary oppositions, for example - cannot take hold in the same ways. Relationality is foundational to decolonizing and Indigenizing education because it fosters empathy, trust, and reciprocity. Cote-Meek emphasizes: "Relationships are vital to creating awareness, building trust, and garnering support in order to mobilize action" (Cote-Meek, 2020, p. xviii).

Decolonizing knowledge fundamentally shifts biases, paradigms, and even world views about sociocultural beliefs, affecting relationships to knowledge, power, and governance. Given that colonial education systems have a history of violence and oppression, built in hierarchical Eurocentric values rooted in reductionist philosophies and individualizing paradigms, decolonizing approaches offer progressive models of collective empowerment by representing a multiplicity of representative voices rather than privileging only a few "experts." Rather, "expertise" is recognized as collectively co-created, held, and shared through reciprocal sharing and learning. We acknowledge, however, that the knowledge shared in a circle, because it reflects the experiences of the people in the circle, is only as diverse as the representative group. Shifting to this paradigm unifies collective efforts to build equitable educational systems.

\section{Doing the Work}

Our intent here is to promote both Indigenous and non-Indigenous facilitation of pedagogical talking circles in an effort to follow the recommendations by UNDRIP and TRC's Calls to Action. However, we invite particularly non-Indigenous educators to respectfully engage with Indigenous pedagogies and methodologies that not only decolonize educational institutions, but 
also encourage relational practices. The TRC specifically points to the Canadian state and the mechanisms of power within it, including citizens and educators, to understand the truth of history and work towards decolonizing before the work of reconciliation can begin.

In order for effective change to occur, non-Indigenous educators who support Indigenous research and teaching have to begin or continue to decolonize learning and teaching (Hare, 2016; Pardy and Pardy, 2020). Acknowledgment is one thing; educated action and integration is another. How do we begin to take steps toward educational action? What are some respectful ways to incorporate Indigenous epistemologies, methodologies, ontologies, and pedagogies in various educational frameworks? How might this process shift power dynamics in an otherwise colonial educational system? These questions of inquiry require some further exploration into the colonial context.

The long history of genocide against Indigenous peoples, communities, and Nations in what is now called Canada must be acknowledged and taught (Reclaiming power and place, 2019). The colonial project is not over, and the Canadian state still perpetuates grievous harms on Indigenous peoples, communities, and Nations through its actions, laws, institutions, and systems. Some examples to sustain this claim include the ongoing apprehension of children through the child welfare system, critical injury and death caused by law enforcement, criminalization leading to over incarceration, and the ongoing violence against and genocide of Indigenous women, girls, and 2SLGBTQQIAA+ identifying individuals. These injustices have been researched and documented extensively in Canada, including in the Royal Commission on Aboriginal Peoples (1996), TRC (2015), and National Inquiry into Missing and Murdered Indigenous Women and Girls (2019).

Educators who take up the work of decolonizing must engage with the history of violence and genocide in Canada. This work should include learning about the Indigenous lands they live and work on and the specific cultures, histories, and languages of the Indigenous peoples, communities, and Nations of those lands. This knowledge is something that should also be built into their teaching in an integrated way. Kimmerer (2021), for example, discusses that in order to decolonize our minds we need to bring Indigenous approaches, knowledges, languages, and principles back into our everyday lives - our very ways of being and knowing. Educators must take up this work with particular attention to their own situatedness and acknowledging how privilege is constituted by and through colonization and other power dynamics, depending on personal experiences and histories.

We do not imagine that this work is without significant challenges. Educators must be prepared to feel uncomfortable and, as a direct consequence, integrate generative ways of addressing their own discomfort — without relying on Indigenous people as their primary supports - as they come to acknowledge their part in colonization. It is also expected that mistakes will be made, and it is essential for educators to learn from their mistakes in doing the work of decolonization. Part of this process is about being accountable and taking responsibility when mistakes occur, while also seeking possible ways of preventing similar mistakes from occurring in the future. In holding people accountable, Carson (2017) notes that while it is 
important to recognize harmful behaviour and language, the work can be done in relational ways. Carson (2017) refers to this approach as calling-in instead of calling-out.

Non-Indigenous peoples can be more than allies when promoting reconciliation by also serving as co-resistors in the process of decolonization. One effective description of this practice, which draws on Simpson (2017), can be found in the Indigenous ally toolkit from the Montreal Urban Aboriginal Community Strategy Network:

Being a co-resistor is about standing together, as an ensemble, in resistance against oppressive forces and requires constant learning. It is combining theory and practice by establishing relationships and being deeply involved within a community that informs how one listens critically, understands an issue and influences the way they go about disrupting oppressive institutions and systemic systems. (Swiftwolfe \& Shaw, 2019)

A significant part of this process is how non-Indigenous people can hold themselves accountable by adopting various forms of emotional, intellectual, and educational labour to address the concept of truth and be supportive co-resistors to Indigenous people.

Including talking circles in classrooms also serves to decolonize institutions by normalizing Indigenous pedagogies and methodologies even in the context of teaching nonIndigenous content. This breaks down the normalized violence of colonial education and supports Indigenous faculty in their work to decolonize and Indigenize universities and schools. Regardless of the challenges it may present, this development can be gradual and still provide impact.

Similar to work in climate justice and sustainability, sexual orientation and gender identity (SOGI), and anti-racism education, Indigenous education can be integrated in all academic subjects and viewed as foundational to teaching and learning. By decolonizing education through pedagogical practices that enact such processes, non-Indigenous educators must be accountable to support UNDRIP and the Calls of the TRC. As Kovach claims, "a decolonizing agenda is a forceful unifier that continues to shape our distinctive experience" (Kovach, 2009, p. 81). Smith and Webber (2018) also propose that the act of incorporating Indigenous knowledges is itself transformative as a way of reducing the influence of colonizing knowledge systems.

In our own teaching experiences doing the work, we have found pedagogical talking circles to be extremely effective when introducing Indigenous pedagogies and methodologies through qualitative methods of storytelling, witnessing, observation, self-reflection, and placebased learning that enhance voice, agency, and representation. The result often creates coconstituted relational and educational spaces to encourage trust, empathy, awareness, support, and, consequently, mobilizing action that leads to transformational change (Cote-Meek, 2020). 


\section{Approaches and Theories}

Before using pedagogical talking circles in our classes or at workshops, we always begin by framing the practice through three primary approaches that are based in Indigenous epistemological knowledge systems: (a) situated relatedness (Johnston, 2018); (b) respectful listening (Johnston, 2018); and (c) reflective witnessing (Clark, 2016; Hunt, 2018). These three approaches provide a framework for asking educators and practitioners, as a self-reflexive process, the following questions: What are we learning from our interactions with others that is counter to our assumptions? Can we acknowledge and, if necessary, take responsibility for our own implicit or explicit biases? How do we hold space for others' learning and development, while simultaneously reflecting about our own processes?

\section{Situated relatedness}

Drawing on the methodology of situated relatedness from Anishinaabe scholar Johnston (2018), which is based upon an epistemology of relationality, we remind participants that examining our own biases remains foundational to this practice. In the most basic terms, situated relatedness asks us to situate ourselves in context to others. It requires everyone in the circle to think about and be mindful of their specific lived history and how that informs their perspectives at all times, especially in relation to other people in the circle who may have differing histories and experiences.

Relationally situating ourselves in the circle, and ultimately outside of it in our social contexts, might be one of the most important features. It is also the reason we have both provided examples of our own practices of situated relatedness here in this section instead of at the introduction of the article (where a statement "situating" or "positioning" ourselves would normally appear). Here are two examples outlining how we might relatedly situate ourselves before beginning a talking circle:

When I (Patricia) facilitate pedagogical talking circles, I am required to situate myself as an Indigenous person within the context of my community and relations because the approach to the work I do as a legal educator is informed by my experiences as a Métis woman. I am also required to situate myself relationally to the Indigenous territory I am living and working on in every instance and my relationship to the sovereign Indigenous Nation/s whose territory I am visiting and/or living on as an uninvited, or sometimes invited, guest. I challenge students to consider how the way we talk about situated relationality is a matter of justice that either perpetuates the acceptance of settler colonial violence as normal, or allows us entry points into disrupting that, as for example, through deliberate interventions such as situated relationality. This includes asking students to think about their relationship to the place/s they have lived and their sociocultural assumptions about their notions of "home" or "homeland." I use my own complex narrative of situated relatedness as an example of how Indigenous epistemological and ontological beingness is translated through the methodological and 
pedagogical practices of the talking circle. I have learned these principles through years of work and practice, and I am especially grateful to Anishinaabe scholar Darlene Johnston, who has been my mentor and whose teaching is instrumental to my pedagogical approach to talking circles.

When I (Derek) facilitate pedagogical talking circles, I am required to situate myself as a non-Indigenous white settler of Norwegian and Welsh ancestry who has also married into an Indigenous family. Next, I situate myself specifically to the Indigenous territory where I currently live and work. I acknowledge how this identity comes with a certain set of responsibilities and accountability. I particularly invite non-Indigenous educators and learners to think about how we can consciously and respectfully support ways of knowing and being that align with Indigenous knowledge systems. As outlined above, nonIndigenous people have responsibilities of decolonizing and Indigenizing education by reducing our unquestioned reliance on Eurocentric forms of practices and knowledges. I tell my own story and how I began this work and why it is valuable and necessary for non-Indigenous educators to take up. I do so in the context of arts-based education and draw on storytelling as a methodology of talking circles. I am mindful of how I approach this practice and how I draw on the teachings and wisdom of Indigenous teachers as guides with humility and respect, taking care in acknowledging proper reference to source materials, people, cultures, and/or languages, and constantly reflecting on any possible biases or assumptions throughout the process.

We are often asked to "position" ourselves in public contexts and that is important. But Johnston (2018) uses situated relatedness as a way of asking people to reflect beyond positionality - to consider the relationships people have to the lands they occupy and live on, the people with whom they have relations, and their personal histories. Ultimately, this work asks us to reflect upon who we are and how that situatedness changes the ways we define our subjective selves in a social or historical context. We ask talking circle participants to think about who they are and where they come from: What is their family history or story of origin? Where were their parents born? We invite them to consider who they are, not based on their education or other achievements that may mark their identities, but by situating themselves relationally to their own or families' histories of being "Canadian" (or not) and what that relationship means to them.

We also ask participants to further contemplate what this all means considering their relationship to the land they live on and the Indigenous peoples of those lands. At the University of British Columbia, for example, it is important for people to consider what it means to live on unceded $\mathrm{x}^{\mathrm{w}} \mathrm{m} ə \theta \mathrm{k}^{\mathrm{w}}$ əyəm (Musqueam) territory, and to reflect on the acknowledgement of "unceded" lands as also containing, in some people's minds, an implied suggestion of the eventual and inevitable cessation of Indigenous jurisdiction by the Canadian state. It is fundamental to question and challenge that implication. According to Cote-Meek (2014), land has always been central to colonization and with it the infrastructures of ideology incorporated in educational systems. 
These questions are just as relevant for Indigenous participants as they are for nonIndigenous participants, albeit in very different ways, and often the crosspollination of perspectives and experiences through respectful and critically self-reflective sharing and listening prove illuminating to everyone in the circle. Thinking about situated relatedness - to the lands we occupy and spend our time on, to the languages we speak, to the people with whom we have relations, to our personal history, in addition to those people around us who are building relationships with us - requires a paradigmatic shift that inherently demands a reckoning with the question: how do I imagine the relationship between education and justice (Barkaskas et al., 2020)?

\section{Respectful listening}

The second approach underpinning the way we practice talking circle pedagogy encourages participants to listen deeply and without judgment (Cowan and Adams, 2002), affording participants to feel seen and heard. Using the term respectful listening, we draw again on Johnston (2018) who considers "deep listening" from an Anishinaabe perspective as a "discipline," which goes beyond simply passive reception. She emphasizes that the discipline of listening in the context of the talking circle is an active practice requiring deep focus on the words and intentions of the person speaking, while also quieting the disruptive internal reactions and responses to their words. In this way, the listener can truly hold space for the speaker and their perspectives without judgment or defensiveness.

The primary features of respectful listening include:

- Employing practices of mutual consideration, recognizing respectful boundaries when challenging others' ideas or introducing sensitive subjects

- Asking participants to focus on their own lived experiences and critically reflect on their perceptions and ideas, which might include multilingual expression

- Experiencing relational encounters to ensure frameworks of responsibility (i.e., holding space for others)

Listening is active and engaging, and draws on other intelligences such as emotional, observational, and somatic (Gladwin, 2021). Respectful listening also fosters compassion and empathy through the mere act of respecting the subjectivity of another person in an extended space and time.

Listening remains an underutilized pedagogical approach in Eurocentric education, largely because listening builds relationships rather than individualized power. Because normative Eurocentric education systems elevate individualism, it is vital to reintroduce interrelational and interconnected ways of knowing and being. The path toward systemic social change involves valuing relationships as a primary focus, with respectful listening as a fundamental practice, rather than the symptoms or the sum of the individual parts. 
What often goes unacknowledged, however, is the fact that relational practices also support individual growth and well-being at the same time as they enhance relationships. Wagamese frames the act of listening as a holistic and an embodied experience:

When you listen, you become aware. That's for your head. When you hear, you awaken. That's for your heart. When you feel, it becomes a part of you. That's for your spirit. Three times. It's so you learn to listen with your whole being. That's how you learn. (Wagamese, 2016, p. 113)

As Wagamese shows, listening is also a practice that promotes various outcomes that both support and go beyond the pedagogical talking circle.

\section{Reflective witnessing}

The third approach of reflective witnessing considers the framework outlined by Kwagiulth scholar Hunt (2018) and Métis scholar Clark (2016) in their research on witnessing as a methodology. They both speak about the power of witnessing, which creates relational encounters to ensure frameworks of responsibility that hold up the experiences of others' lives we have witnessed, particularly on their own terms. Reflective witnessing invites participants to hold space for a person's perspectives, even though they may not be the same as our own, and then reflecting on feelings and thoughts that they may generate based on the relational exchange of hearing someone speak from their lived experience. Reflective witnessing is ultimately a practice of accountability and responsibility.

The facilitator of the pedagogical talking circle, which for our purposes is the instructor/teacher, guides and models the process for the participants/students by opening and closing the circle to demonstrate how to participate - that is, how to be a reflective witness. This creates the container for reflective witnessing and the facilitator's job is to hold space for that throughout the process. The facilitator also explains and models respectful behaviour based upon the three main methodologies of situated relatedness, respectful listening, and reflective witnessing. In our experiences over the past several years, introducing and practicing talking circles encourages respectful behaviour and there are rarely any behavioural issues. Much of this success has to do with framing the session as we have outlined here using these three approaches.

Before opening the circle, for example, participants are asked to agree that they will avoid responding directly through contradiction or confrontation to particular experiences or reflections of others (respectful listening). Participants are instead asked to focus on their own experiences and critically reflect on their perceptions and ideas (reflective witnessing). This may include feelings and thoughts about what other participants have said. The purpose is to connect back to our own perceptions and ideas, and to reflect on why we may feel the way we do or think about a specific issue in a particular way, while examining any biases or assumptions that may come up for us in the process (situated relatedness). 


\section{General Protocol}

Reflective witnessing, as well as situated relatedness and respectful listening, requires some basic protocol when using pedagogical taking circles. ${ }^{\text {iv }}$ This process usually requires a symbolic talking object. We each use a talking stick, for example, typically a carved cedar hummingbird (Patricia) and a carved cedar raven feather (Derek), both of which were created by the Kwaguith artist Alex Mountain. Any symbolic object, such as a stone, feather, or cedar bough, can be used. The aim is to find anything that reminds participants they are also linked holistically to the world outside of the intellectual or educational space where the circle may be happening.

As participants pass the talking object around, only the person holding it speaks and everyone must listen without interrupting. Participants must be informed that they are allowed to "pass" if they do not want to share. This is particularly significant for ensuring Indigenous students do not feel they are required to share their experiences as an added weight of teaching their peers. When responding, participants must follow a protocol of mutual consideration, which recognizes respectful boundaries by not directly challenging others' ideas, or introducing sensitive subject matter thoughtfully into the collective sharing space.

In cases where formal ethics must be granted for a pedagogical talking circle, such as support or therapy groups or with underaged participants outside of formal educational contexts, facilitators would collect consent forms before the activity begins. Although educational talking circles do not often require this type of formal consent, such as in the cases of transformative justice or therapeutic talking circles, it is still necessary to ensure participants consent to being in the circle after the theoretical approaches and methodology are explained to them.

Part of consenting to the circle is agreeing to avoid using discriminatory, bigoted, or violent speech, as well as agreeing to be (to the best of one's ability) self-aware and selfreflective when speaking and listening. Participant learners also consent to avoiding sharing any self-reflections of others' outside of the circle. Instead, they agree to listen, witness, and be accountable to what has been shared in the circle without taking ownership of other peoples' words and experiences.

\section{Conclusion}

As a supportive learning space, we draw on theoretical approaches outlined above as the three main principles for methodology and praxis of situated relatedness, respectful listening, and reflective witnessing. Although this process has been adapted over time through practice and offers our pedagogical perspectives through our own experiences, there are many other effective approaches to talking circles, some of which include Running Wolf and Rickard (2003), Bohanon (2006), Granillo et al. (2010), Haozous et al. (2010), Kaminski (2011), Justice Institute of British Columbia (2016), Wilken and Nunn (2017), Zizka (2017), and Brown \& Di Lallo (2020). Critical approaches to pedagogical talking circles are, as outlined in this article, somewhat distinct from other models, even if the application might share many similarities. 
Pedagogical talking circles create spaces for exchanging ideas and views, whether similar or dissimilar, with the intentional commitment to meeting each person where they are at in their learning journey. They also provide one of many possible examples that can be used by educators who are committed to decolonizing their pedagogical practices. Educational talking circles are ultimately a beneficial praxis-based approach that Indigenous and non-Indigenous facilitators can use to create supported and relational learning environments. Developing respectful practices around Indigenous pedagogy and methodology requires practice, respect, and accountability, and we encourage educators to consider using the methodology and praxis of pedagogical talking circles in their own educational contexts, while also learning more about how to further decolonize and Indigenize education.

\section{Acknowledgments}

The authors are appreciative to their students, both in the faculties of Law and Education at the University of British Columbia, who have respectfully and responsibly taken up the practice of pedagogical talking circles. These students have helped to create and spread the reciprocal learning environment that makes relational pedagogy possible. We are also grateful for the mentorship of Anishinaabe Professor Darlene Johnston when considering methodologies to support pedagogical talking circles in educational contexts.

\section{Author Bio}

Patricia Miranda Barkaskas is a Métis lawyer and educator. She is an Associate Professor of Teaching and the Academic Director of the Indigenous Community Legal Clinic, Peter A. Allard School of Law at the University of British Columbia. Her research and teaching focus on access to justice for Indigenous people and decolonizing and Indigenizing law. She utilizes Indigenous pedagogies to disrupt the normative violence of colonial legal education with a particular focus on experiential learning, clinical legal education, and skills-based legal training.

Derek Gladwin is Assistant Professor of Language and Literacy Education and a Sustainability Fellow the University of British Columbia. His research and teaching aim to promote social understanding and relational action on environmental, health and well-being, and arts-based approaches through public forms of education and literacy. He is the author or editor of several books, including Rewriting our stories (2021), and serves as Senior Editor of the Oxford Encyclopedia of Environmental \& Sustainability Education with Oxford University Press. 


\section{References}

Archibald, J. (2013). Indigenous storywork: Educating the heart, mind, body, and spirit. UBC Press.

Barkaskas, P. (2020). Decolonizing the "contemporary left"?: An Indigenous reflection on justice in the new world order. In S. Gandesha (Ed.), Spectres of fascism: Historical, theoretical and international perspectives (pp. 191-206). Pluto Press.

Barkaskas, P., Alcorn, M., Adair, R., Gotziaman, K., Mackie, J., Northcote, M., \& Wicks, V. (2020). Reflecting on clinical legal education at the Indigenous Community Legal Clinic. Journal of Law and Social Policy, 32, 138-157.

Battiste, M. (2013). Decolonizing education: Nourishing the learning spirit. Purich Publishing.

Battiste, M. (2000). Reclaiming Indigenous voice and vision. UBC Press.

Bohanon, J. P. (2006, June 12-15). The talking circle: A perspective in culturally appropriate group work with Indigenous Peoples [Conference proceedings]. 6th International Conference on Diversity in Organisations Communities and Nations, New Orleans, LA, United States.

Brown, M., \& Di Lallo, S. (2020). Talking circles: A culturally responsive evaluation practice. American Journal of Evaluation, 41(3), 367-383.

Carson, Q. (2017, August). Pedagogy of the decolonizing [Video]. TEDxUAlberta. https://www.youtube.com/watch?v=IN17Os8JAr8

Clark, N. (2016). Red intersectionality and the violence-informed witnessing praxis with Indigenous girls. Girlhood Studies, 9(2), 46-64.

Cote-Meek, S. (2014). Colonized classrooms: Racism, trauma and resistance in post-secondary education. Fernwood.

Cote-Meek, S. (2020). From colonized classrooms to transformative change in the academy: We can and must do better! In S. Cote-Meek \& T. Moeke-Pickering (Eds.), Decolonizing and Indigenising education in Canada (pp. xi-xxiii). Canadian Scholars.

Coke-Meek, S., \& Moeke-Pickering, T. (Eds.). (2020). Decolonizing and Indigenizing education in Canada. Canadian Scholars.

Coupal, M. (2020). Reconciliation rainbows and the promise of education: Teaching truth and redress in neocolonial Canada. In S. Cote-Meek \& T. Moeke-Pickering (Eds.), Decolonizing and Indigenising education in Canada (pp. 211-227). Canadian Scholars.

Cowan, D. A., \& Adams, K. (2002). Talking circles as a metaphor and pedagogy for learning [Paper presentation]. The Association of Leadership Educators' Conference, Lexington, KY, United States. https://www.leadershipeducators.org/Resources/Documents/ Conferences/Lexington/cowan_and_adams_talking_circle.pdf

Di Lallo, S., Graham, L., \& Arian, M. (2018). The Stollery Awasisak Indigenous health program: Community engagement talking circles phase II. Alberta Health Services. 
Donnan, M.E., Aitken, A., \& Manore, J.L. (2020). 'If not here, where?': Making decolonization a priority at an undergraduate university. In S. Cote-Meek \& T. Moeke-Pickering (Eds.), Decolonizing and Indigenising education in Canada (pp. 193-210). Canadian Scholars.

Emerson, L. (2014). Diné culture, decolonization, and the politics of Hozho. In L.L. Lee (Ed.), Diné perspectives: Revitalizing and reclaiming Navajo thought (pp. 49-67). University of Arizona Press.

Fickel, L. H. (2005). Teachers, tundra, and talking circles: Learning history and culture in an Alaska Native village. Theory and Research in Social Education, 33(4), 476-507.

First Nation Pedagogy Online. (2009). Talking Circles. http://firstnationspedagogy.ca/ Circletalks.html

Galla, C. K., \& Holmes, A. (2020). Indigenous thinkers: Decolonizing and transforming the academy through Indigenous relationality. In S. Cote-Meek \& T. Moeke-Pickering (Eds.), Decolonizing and Indigenising education in Canada (pp. 51-72). Canadian Scholars.

Gladwin, D. (2021). Rewriting our stories: Education, empowerment, and well-being. Cork University Press.

Grafton, E., \& Melançon, J. (2020). The dynamics of decolonization and Indigenization in an era of academic "Reconciliation". In S. Cote-Meek \& T. Moeke-Pickering (Eds.), Decolonizing and Indigenising education in Canada (pp. 135-154). Canadian Scholars.

Granillo, B., Renger, R., Wakelee, J., \& Burgess, J. L. (2010). Utilization of the Native American talking circle to teach incident command system to tribal community health representatives. Journal of Community Health, 35, 625-634.

Haozous, E.A., Eschiti, V., Lauderdale, J., Hill, C., \& Amos, C. (2010). Use of the talking circle for Comanche women's breast health education. Journal of Transcultural Nursing, 21(2), 377-385.

Hare, J. (2016). 'All of our responsibility': Instructor experiences with required Indigenous education courses. Canadian Journal of Native Education, 38(1), 101-120.

Hare, J., \& Davidson, S. F. (2016). Learning from Indigenous knowledge in education. In D. Long \& O. P. Dickason (Eds.), Visions of the heart: Canadian Aboriginal issues (pp. 241262). Oxford University Press.

Hodge, F. S., Fredericks, L., \& Rodriguez, B. (1996). American Indian women's talking circle: A cervical cancer screening and prevention project. Cancer, 78(7), 1592-97.

Hunt, S. (2018). Researching within relations of violence: Witnessing as methodology. In D. McGregor, J-P. Restoule, \& R. Johnston (Eds.), Indigenous research: Theories, practices, and relationships (pp. 282-295). Canadian Scholars.

Johnston, D. (2018, May). Disrupting normative legal education through decolonial resistance Pedagogy [Workshop on Legal Pedagogy]. Peter A. Allard School of Law, University of British Columbia, Vancouver.

Justice Institute of British Columbia. (2016). Aboriginal disaster resilience knowledge sharing toolkit. (2016). Office of Applied Research \& Graduate Studies, School of Public Safety. https://adrp.jibc.ca/resilience-knowledge-sharing-toolkit/ 
Kaminski, J. (2011). Talking circles. First Nations Pedagogy. https://firstnationspedagogy.com/ talkingcircles.html

Kimmerer, R. W. (2021, January). A conversation with Dr. Robin Wall Kimmerer [video]. Forestry and Simon K.Y. Lee Global Lounge and Resource Centre, University of British Columbia.

Kovach, M. (2009). Indigenous methodologies: Characteristics, conversations, and contexts. University of Toronto Press.

Kovach, M. (2021, March). In good relations: Ethics, and reciprocity within Indigenous research [Video webinar]. Learning Circle, University of British Columbia. https://learningcircle.ubc.ca/2021/02/ margaret-kovach-in-good-relations-ethics-and-reciprocity-within-indigenous-research/

National Inquiry into Missing and Murdered Indigenous Women and Girls (2019). Reclaiming power and place: the final report of the National Inquiry into Missing and Murdered Indigenous Women and Girls-Executive Summary. https://www.mmiwg-ffada.ca/ final-report/

Pardy, L., \& Pardy, B. (2020). Decolonizing non-Indigenous faculty and students: Beyond comfortable diversity. In S. Cote-Meek \& T. Moeke-Pickering (Eds.), Decolonizing and Indigenising education in Canada (pp. 229-246). Canadian Scholars.

Picou, J. S. (2000). The 'Talking Circle' as sociological practice: Cultural transformation of chronic disaster impacts. Sociological Practice, 2(2), 77-97.

Royal Commission on Aboriginal Peoples. (1996). Report of the Royal Commission on Aboriginal Peoples. Government of Canada. https://www.bac-lac.gc.ca/eng/discover/ aboriginal-heritage/royal-commission-aboriginal-peoples/Pages/final-report.aspx

Running Wolf, P., \& Rickard, J. A. (2003). Talking circles: A Native American approach to experiential learning. Journal of Multicultural Counseling and Development, 31, 39-43.

Sams, J. (1990). Sacred path cards: The discover of self through native teachings. HarperSanFrancisco.

Simpson, L. B. (2017). As we have always done: Indigenous freedom through radical resistance. University of Minnesota Press.

Smith, G., \& Webber, M. (2018). Transforming research and Indigenous education struggle. In E. McKinley \& L. Smith (Eds.), Handbook of Indigenous education (pp. 813-822). Springer.

Styres, S. (2017). Pathways for remembering and recognizing Indigenous thought in education: Philosophies of Iethi'nihsténha Ohwentsia'kékha (Land). University of Toronto Press.

Swiftwolfe, D., \& Shaw, L. (2019). Indigenous ally toolkit. Montreal urban Aboriginal community strategy network. https://gallery.mailchimp.com/ 86d28ccd43d4be0cfc11c71a1/files/102bf040-e221-4953-a9ef-9f0c5efc3458/Ally_email.pdf

Tachine, A. R., Yellow Bird, E., \& Cabrera, N. (2016). Sharing circles: An Indigenous methodological approach for researching with groups of Indigenous peoples. International Review of Qualitative Research, 9, 277-295. 
Truth and Reconciliation Commission of Canada. (2015). Truth and Reconciliation Commission of Canada: Calls to Action. Truth and Reconciliation Commission of Canada. http://trc.ca/assets/pdf/Calls_to_Action_English2.pdf

United Nations Declaration on the Rights of Indigenous Peoples. (2007). GA Res 295, UNGAOR, 61 ${ }^{\text {st }}$ Sess, Supp No 49, UN Doc A/RES/61/295, 46 ILM 1013. https://undocs.org/A/RES/61/295

United Nations Permanent Forum on Indigenous Issues. (2009). Indigenous Peoples, Indigenous Voices [Factsheet]. https://www.un.org/esa/socdev/unpfii/documents/

5session_factsheet1.pdf

Wagamese, R. (2016). Embers: One Obibway's meditations. Douglas \& McIntyre.

Watters, H. (June 1, 2015). Truth and Reconciliation chair urges Canada to adopt UN declaration on Indigenous Peoples. CBC News. https://www.cbc.ca/news/politics/ truth-and-reconciliation-chair-urges-canada-to-adopt-un-declaration-on-indigenous-peoples 1.3096225

Wilken, M., \& Nunn, M. (2017). Talking circles to improve diabetes self-care management. The Diabetes Educator, 43(4), 388-395.

Zizka, L. (2017). From campfire to classroom: An application of talking circles and storytelling in hospitality management education. Journal of Hospitality \& Tourism Education, 29(1), 44-50.

\section{JL}

${ }^{\mathrm{i}}$ Both authors acknowledge their co-equal efforts in contributing to this publication by listing surnames alphabetically. Building on relational models, rather than hierarchical models of first and second authors, both authors support the process of co-creation and co-publication in this collaborative process.

ii We use the term "Indigenous" throughout - drawing on the United Nations Permanent Forum on Indigenous Issues (2009) framework of Indigenous Peoples acknowledging 370 million Indigenous Peoples across the globe with distinct languages, traditions, and cultures (see also Cote-Meek, 2020) - as an inclusive way to think globally about decolonization and Indigeneity. In Canada, First Nations, Métis, and Inuit are legally recognized as Indigenous Peoples. However, definitions and questions around identity in Canada or around the world may not apply to all Indigenous people.

iii As an Indigenous person, a femme-identified queer Métis cisgender woman, my work in the university specifically takes up intervening in the normative violence of colonial education, in particular legal education, and working for and with Indigenous peoples, communities, and Nations in their ongoing resistance to the Canadian state. My perspective on decolonizing and Indigenizing education is that it is possible and necessary work that must be done by both Indigenous and non-Indigenous people. I uphold the criteria of accountability and responsibility in doing this work and the foundational principle that it cannot be done on the backs of Indigenous students, staff, and faculty in the post-secondary setting (or other educational settings), or in ways that continue to cause harm to Indigenous peoples, communities, and Nations. It is my position that we need our non-Indigenous allies, accomplices, and co-resistors to engage in this work with us and accept the burden of discomfort this may cause. I also accept that we will not be perfect in the work of decolonizing and Indigenizing education and that mistakes will be made - 
these must be owned up to and a light shone on them in order to address what needs fixing to move forward with the work. I also know that not all Indigenous people share my perspectives on these issues. I respect Indigenous perspectives that are different from my own on these matters, even while I feel I must continue to do my work through these interventions and support non-Indigenous educators in their efforts to do this work as well.

iv Rather than offer a "how to" application of how we use talking circles, we first decided to provide a critical framework outlining the pedagogical methodologies and theories supporting this practice and the ways they support efforts to decolonize and Indigenize education. Although we are working on an open access toolkit for pedagogical talking circles aimed at educators, other open access resources are also available. See, for example, First Nation Pedagogy Online (2009), Kaminski (2011), and the Aboriginal disaster resilience knowledge sharing toolkit through the Justice Institute of British Columbia (2016). 